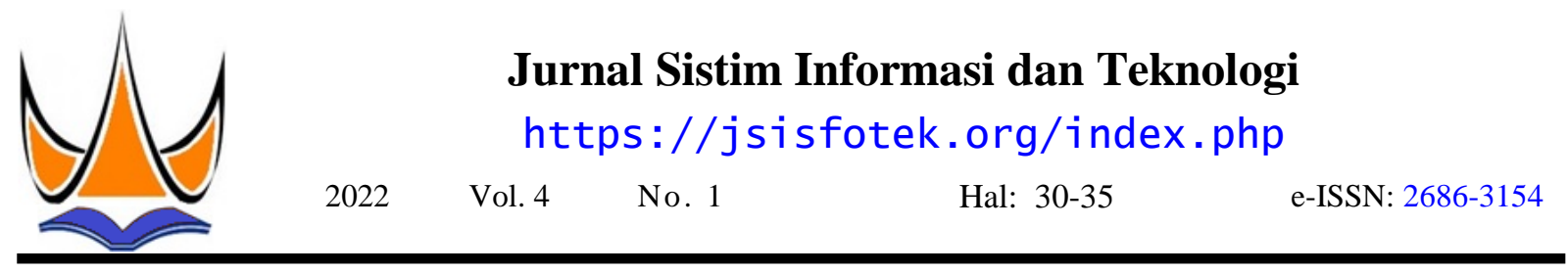

\title{
Analisis Penerimaan terhadap Penggunaan E-Learning Menggunakan Metode Technology Acceptance Model (TAM)
}

\author{
Idria Maita $^{1 \bowtie}$, Sayogi Majid ${ }^{2}$ \\ ${ }^{1,2}$ Universitas Islam Negeri Sultan Syarif Kasim Riau \\ idria@uin-suska.ac.id
}

\begin{abstract}
E-learning is a network-based learning system. Universitas Islam Negeri (UIN) Sultan Syarif Kasim Riau has had Moodlebased e-learning for a long time, but during the Covid-19 pandemic, UIN Suska Riau e-learning saw massive use. The main users of e-learning are students and teachers, there are barriers in using e-learning, namely, users have difficulty in understanding functions and lack of socialization in using e-learning. The limitations experienced will affect the acceptance of e-learning users. The aim of this study was to determine the acceptance of the use of e-learning. The Technology Acceptance Model (TAM) method can measure the level of user acceptance, in this study using three modified TAM method variables, namely the variable "perceived usefulness" from "perceived usefulness", the variable "perceived usability" and the variable "Acceptance of IT Acceptance". The study sample comprised 100 students and 40 teachers. Process data analysis using PLS-SEM with SmartPLS 3.0. The results of the hypothesis obtained from the interviewees of lecturers and students are the variable Perceived usefulness, Perceived user-friendliness has a positive effect on IT acceptance. It is concluded that users can benefit from using e-learning.
\end{abstract}

Keywords: E-learning, Moodle, Partial Least Square-Structural Equation Modeling (PLS-SEM), Networking, Technology Acceptance Model (TAM).

\begin{abstract}
Abstrak
E-learning merupakan sistem pembelajaran berbasis jaringan. Universitas Islam Negeri (UIN) Sultan Syarif Kasim Riau telah lama memiliki e-learning yang berbasis Moodle, namun pada saat ini $e$-learning UIN Suska Riau digunakan secara masif. Pengguna utama e-learning ini adalah mahasiswa dan dosen, dalam penggunaan e-learning terdapat kendala yaitu pengguna kesulitan dalam memahami fitur dan kurangnya sosialisasi dalam penggunaan e-learning. Kendala yang dialami akan mempengaruhi dari penerimaan pengguna e-learning. Tujuan penelitian ini untuk mengetahui penerimaan dari penggunaan e-learning. Metode Technology Acceptance Model (TAM) dapat mengukur tingkat penerimaan pengguna, dalam penelitian ini terdapat tiga variabel metode TAM yang sudah dimodifikasi yaitu variabel persepsi kegunaan (Perceived Usefulness), variabel kemudahan penggunaan (Perceived Easy of Use) dan variabel penerimaan (Acceptance of IT). Sampel penelitian adalah mahasiswa 100 orang dan dosen 40 orang. Analisis proses data menggunakan PLS-SEM dengan SmartPLS 3.0. Hasil hipotesis yang diperoleh pada responden dosen dan mahasiswa adalah variabel Perceived Usefulness. Perceived Ease of Use terdapat pengaruh positif terhadap Acceptance of IT. Kesimpulannya adalah pengguna dapat menerima dari penggunaan e-learning.
\end{abstract}

Kata kunci: E-learning, Moodle, Partial Least Square-Structural Equation Modeling (PLS-SEM), Networking, Technology Acceptance Model (TAM).

(C) 2022 JSisfotek

\section{Pendahuluan}

E-learning merupakan proses pembelajaran berbasis internet dalam rangka menjadikan siswa lebih mandiri dan meningkatkan pembelajaran yang berpusat pada pelajar [1]. Dengan adanya e-learning pelajar diharapkan mampu berkembang dengan baik dalam memahami pelajaran apabila mereka menggunakan $e$ learning [2]. Dengan menggunakan e-learning proses pembelajaran tidak memerlukan interaksi tatap muka antara dosen atau pengajar, sehingga proses pembelajaran dapat lebih efektif dan juga adanya forum tanya jawab serta kemudahan dalam mengakses materi [3]. E-learning dapat dianggap sebagai sarana yang baik sebagai fasilitas proses penyampaian belajar mengajar [4].
Dikarenakan pembelajaran berbasis teknologi memainkan peranan penting dalam bidang pendidikan [10]. Universitas Islam Negeri Sultan Syarif Kasim Riau meluncurkan e-learning guna menunjang proses pembelajaran dan telah berjalan 12 tahun. Untuk membangun e-learning, pihak Pusat Informasi Pangkalan Data menggunakan moodle (Modular Object-Oriented Dynamic Learning Environment) yang menjadi pilihan UIN Suska Riau dalam pengembangan e-learning ..

Penggunaan e-learning memiliki beberapa masalah dan kesulitan yang disadari pengguna, dan beberapa kendala yang menyulitkan pengguna untuk berinteraksi dengan platform ini. Berdasarkan pengamatan secara langsung dan kuesioner yang berisikan beberapa pertanyaan dan diberikan kepada 
responden, pemasalahan yang dialami pada pengguna adalah pengguna kesulitan dalam penggunaan fiturfitur di dalam $e$-learning, tampilan interface sistem $e$ learning yang kurang ramah pengguna dan website $e$ learning yang lambat dan sering terjadi error saat penggunaan.

Permasalahan yang dialami dalam penggunaan $e$ learning akan mempengaruhi terhadap minat serta penerimaan dalam menggunakan sistem e-learning UIN Suska Riau tersebut. Terdapat berbagai macam teori dan model dari konsep penerimaan teknologi, dalam model penerimaan teknologi digunakan dalam mengidentifikasi perilaku pengguna suatu teknologi informasi [5].

Menurut Al-Qaysi, Mohamad-Nordin, dan Al-Emran berdasarkan dari tinjauan sistematis penerapan metode TAM di dalam bidang pendidikan telah terbukti ke efektifannya di bandingkan dengan metode teoritis lainnya [9]. Berdasarkan tinjauan sistematis tentang studi penerimaan e-learning memperlihatkan bahwa TAM adalah teori yang paling sering digunakan dalam sebuah penelitian tentang penerimaan e-learning [6],[8]. Dengan persentase sebesar $86 \%$ penelitian menggunakan TAM sebagai teori dasar [7].

Pengukuran dari tingkat penerimaan penggunaan suatu teknologi informasi dapat menggunakan metode analisis dengan metode Technology Acceptance Model (TAM). TAM memiliki dua konstruk utama yaitu persepsi kegunaan Perceived Usefulness (PU) dan persepsi kemudahan Perceived Ease of Use (PEU) [8].

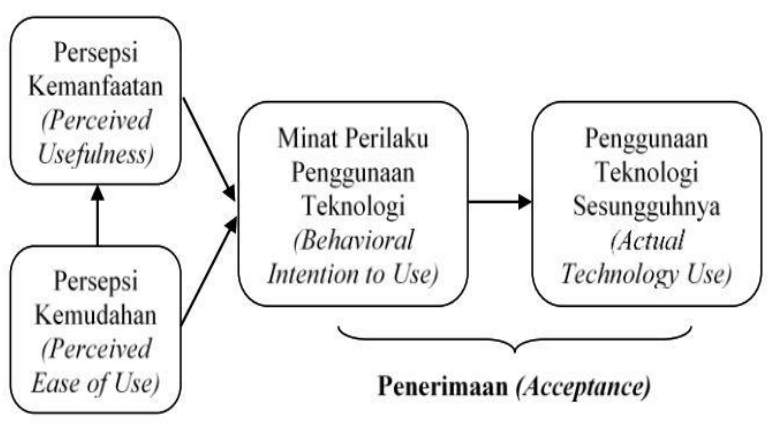

Gambar 1. Technology Acceptance Model

Pada Gambar 1 persepsi kegunaan pada variabel ini dapat memberikan gambaran seseorang terhadap penggunaan suatu sistem informasi bahwa dengan menggunakan sistem informasi tersebut dapat memberikan manfaat baginya. Persepsi kemudahan pada variabel kemudahan menggambarkan kepercayaan pengguna terhadap suatu sistem informasi yang digunakan dapat mempermudah pekerjaannya, diantaranya dapat mengurangi waktu dan tenaga [10].

Tujuan dari penelitian ini menggunakan Technology Acceptance Model untuk mengetahui penerimaan pengguna berdasarkan variabel TAM yaitu variabel kemudahan (PU), variabel kegunaan (PEU) dan variabel penggunaan sebenarnya. Diharapkan dapat mengetahui tentang pengaruh variabel manfaat (PU), variabel kemudahan (PEU) dan Acceptance of IT (ACC) penerimaan terhadap penggunaan e-learning UIN Suska Riau.

\section{Metodologi Penelitian}

Pada Gambar 2 merupakan metodologi dari penelitian yang akan dilaksanakan guna mengetahui penerimaan dari pengguna e-learning .

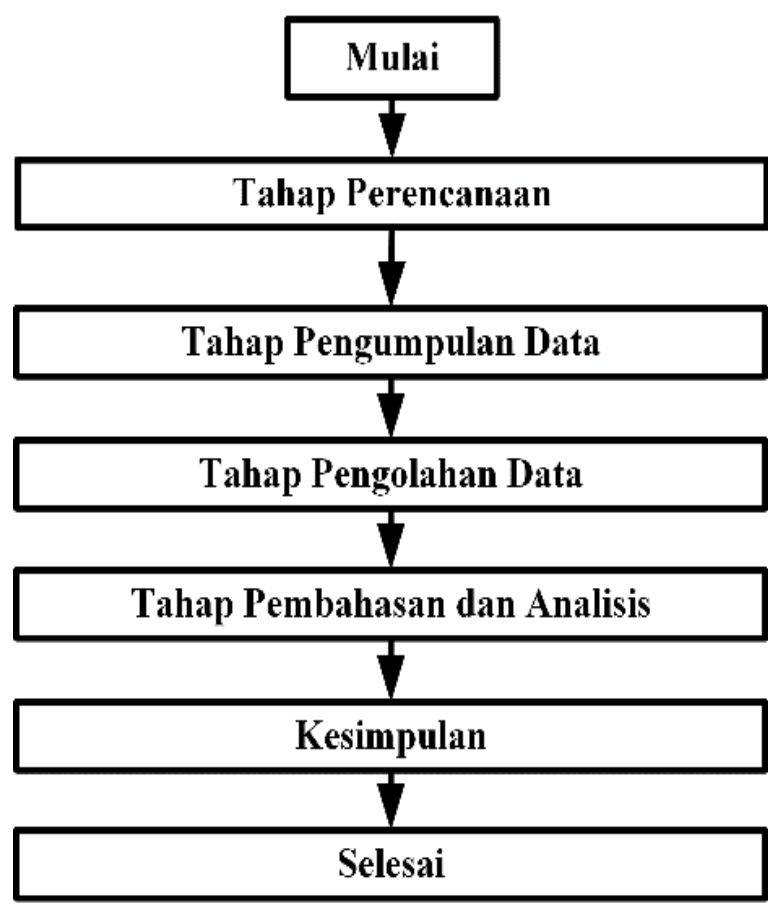

Gambar 2. Metodologi Penelitian

\subsection{Tahap Perencanaan}

Terdapat beberapa poin penting dalam tahapan perencanaan penelitian yang terdiri dari identifikasi masalah penelitian, rumusan dan batasan masalah, tujuan dan manfaat penelitian, menetukan responden serta hipotesis penelitian Terdapat 3 hipotesis penelitian yaitu:

\section{H1: PEU berpengaruh signifikan terhadap ACC.}

H2: PU berpengaruh signifikan terhadap ACC.

H3: PU dan PEU sama-sama berpengaruh signifikan terhadap ACC.

\subsection{Tahap Pengumpulan Data}

Pada tahapan pengumpulan data penelitian yaitu observasi, wawancara kepada responden dan penanggung jawab dari e-learning, dan menyebarkan kuesioner kepada respondenn dengan pengukuran skala likert 4 titik. 


\subsection{Tahap Pengolahan Data}

Pada tahapan pengolahan data digunakan Partial Least Square-Structural Equation Model (PLS-SEM) yang berguna sebagai perhitungan statistik terutama dalam pengembangan teori penelitian eksplorasi. Pertama adalah mendriksipkan responden dari pengguna $e$ learning, uji outer model yang terdiri dari convergent validity dan discriminant validity. Pada uji inner model terdiri dari uji coefficient of determination $\left(r^{2}\right)$, uji effect size $\left(\mathrm{f}^{2}\right)$, predictive relevance $\left(\mathrm{Q}^{2}\right)$ dan T-test.

\section{Pembahasan dan Analisis}

Tahapan analisis adalah dengan menggunakan metode Technology Acceptance Model (TAM) berdasarkan variabel diantaranya adalah variabel persepsi Perceived Ease of Use, variabel Perceived Usefulness dan variabel Acceptance of IT dan dapat dilihat pada Gambar 3.

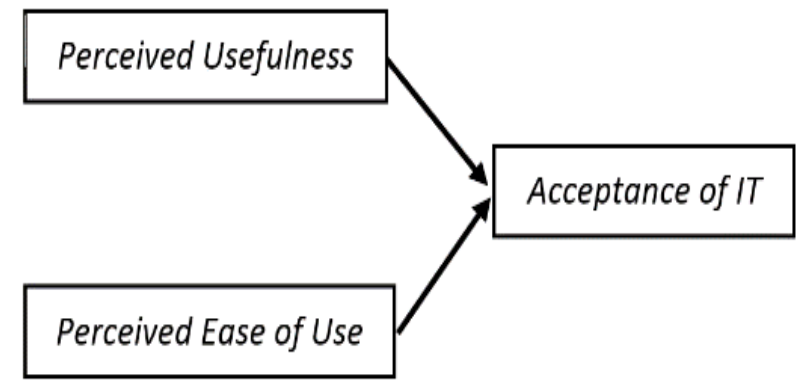

Gambar 3. Kerangka Penelitian

\section{Hasil dan Pembahasan.}

\subsection{Variabel Penelitian}

Dengan menggunakan variabel PU dan PEU sebagai variabel independen atau variabel yang tidak terikat atau dapat mempengaruhi dan ACC sebagai variabel dependen atau variabel yang dipangaruhi, dapat dilihat pada Tabel 1 .

Tabel 1. Variabel Penelitian

\begin{tabular}{lll}
\hline Variabel & \multicolumn{1}{c}{ Indikator } & Kode \\
\hline & 1. Workmore Quickly & PU1 \\
Perceived & 2. Job Performance & PU2 \\
Usefulness & 3. Increase Productivity & PU3 \\
(PU) & 4. Effectiveness & PU4 \\
& 5. Makes Job Easier & PU5 \\
& 6. Usefull & PU6 \\
\hline Variabel & \multicolumn{1}{c}{ Indikator } & Kode \\
\hline \multirow{3}{*}{ Perceived } & 1. Easy to Learn & PEU1 \\
Ease of & 3. Cleartrollable and Understandable & PEU2 \\
Use & 4. Fexible & PEU4 \\
(PEOU) & 5. Easy to Become Skillful & PEU5 \\
& 6. Easy to Use & PEU6 \\
\hline Variabel & \multicolumn{1}{c}{ Indikator } & Kode \\
\hline \multirow{2}{*}{ Acceptance } & 1. Rasa Terbantu & ACC1 \\
of IT & 2. Menerima Penerapan TI & ACC2 \\
(ACC) & 3. Fitur Sudah Lengkap & ACC3 \\
& 4. Puas Dengan Sistem & ACC4 \\
\hline
\end{tabular}

\subsection{Karakteristik Responden}

Karakteristik jenis kelamin responden disajikan pada Tabel 2 dan Tabel 3, lama penggunaan sistem pada Tabel 4 dan Tabel 5. Sampel penelitian menggunakan simple random sampling dan jumlah sampel di tentukan dengan rumus slovin dan didapatkan 100 responden mahasiswa dan 40 responden dosen UIN Suska Riau.

a. Jenis Kelamin

Tabel 2. Jenis Kelamin Mahasiswa

\begin{tabular}{ccc}
\hline Jenis Kelamin & Jumlah & Persentasi (\%) \\
\hline L & 54 & 54 \\
P & 46 & 46 \\
\hline Total & 100 & 100 \\
\hline
\end{tabular}

Tabel 3. Jenis Kelamin Dosen

\begin{tabular}{ccc}
\hline Jenis Kelamin & Jumlah & Persentasi (\%) \\
\hline L & 25 & 63 \\
P & 15 & 38 \\
\hline Total & 40 & 100 \\
\hline
\end{tabular}

b. Lama Penggunaan Sistem

Tabel 4. Lama Penggunaan Sistem Mahasiswa

\begin{tabular}{ccc}
\hline & Jumlah & Persentasi (\%) \\
\hline <2 Tahun & 89 & 89 \\
2-3 Tahun & 11 & 11 \\
\hline Total & 100 & 100 \\
\hline
\end{tabular}

Tabel 5. Lama Penggunaan Sistem Mahasiswa

\begin{tabular}{ccc}
\hline & Jumlah & Persentasi (\%) \\
\hline$<2$ Tahun & 34 & 85 \\
2-3 Tahun & 5 & 13 \\
$>3$ Tahun & 1 & 3 \\
\hline Total & 40 & 100 \\
\hline
\end{tabular}

\subsection{Analisa Data}

Model pengukuran dan struktur model dianalisis melalui diagram analisis jalur menggunakan SmartPLS 3.0. Analisis perhitungan dilakukan menggunakan algoritma PLS yang menggambarkan analisis jalur (path analysis) hubungan dalam sistem persamaan struktural dalam diagram jalur pada Gambar 4.

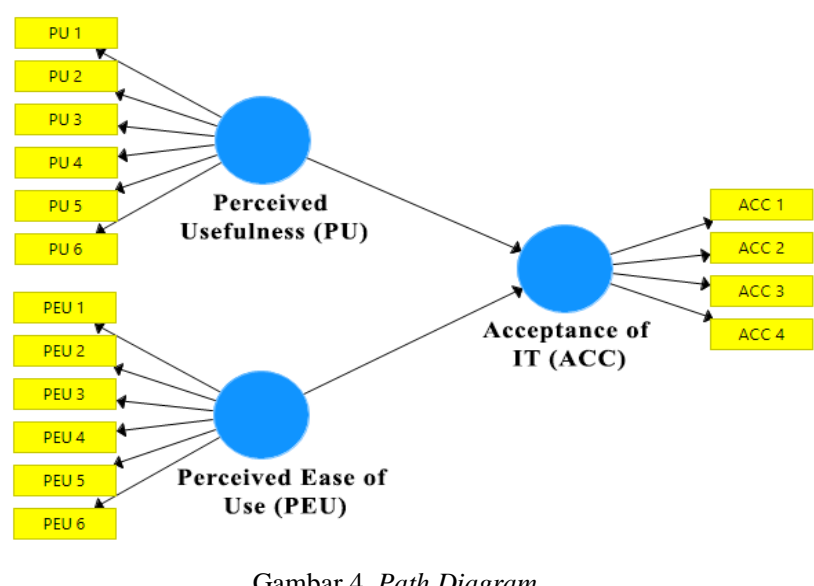

Gambar 4. Path Diagram 


\subsection{Model Pengukuran (Outer Model)}

a. Nilai Convergent validity Mahasiswa

Pada Tabel 6 nilai loading factor mahasiswa $(>0,7)$ dan dosen loading factor $(>0,7)$. Terdapat nilai satu indikator dengan loading factor $(<0,7)$ namun tetap dapat digunakan. Tabel 7 menampilkan nilai dari loading factor dosen.

Tabel 6. Outer Loading Mahasiswa

\begin{tabular}{lccc}
\hline Variabel & Skor & Kode & Ket \\
\hline & 0,815 & PU1 & \\
Perceived & 0,858 & PU2 & \\
Usefulness & 0,791 & PU3 & Valid \\
(PU) & 0,854 & PU4 & \\
& 0,777 & PU5 & \\
\hline Variabel & 0,791 & PU6 & \\
\hline & Skor & Kode & \\
Perceived & 0,788 & PEU1 & \\
Ease of Use & 0,850 & PEU2 & \\
(PEOU) & 0,856 & PEU3 & Valid \\
& 0,808 & PEU4 & \\
& 0,845 & PEU5 & \\
\hline Variabel & 0,811 & PEU6 & \\
\hline & Skor & Kode & \\
Acceptance of & 0,844 & ACC1 & \\
IT (ACC) & 0,819 & ACC2 & Valid \\
& 0,758 & ACC3 & \\
& 0,863 & ACC4 & \\
\hline
\end{tabular}

Tabel 7. Outer Loading Dosen

\begin{tabular}{lccc}
\hline Variabel & Skor & Kode & Ket \\
\hline & 0,889 & PU1 & \\
Perceived & 0,821 & PU2 & \\
Usefulness & 0,674 & PU3 & Valid \\
(PU) & 0,789 & PU4 & \\
& 0,887 & PU5 & \\
\hline Variabel & 0,923 & PU6 & \\
\hline & Skor & Kode & \\
Perceived & 0,752 & PEU1 & \\
Ease of Use & 0,876 & PEU2 & Valid \\
(PEOU) & 0,918 & PEU3 & \\
& 0,931 & PEU4 & \\
& 0,808 & PEU5 & \\
\hline Variabel & 0,874 & PEU6 & \\
\hline & Skor & Kode & \\
Acceptance of & 0,827 & ACC1 & \\
IT (ACC) & 0,904 & ACC2 & Valid \\
& 0,852 & ACC3 & \\
\hline
\end{tabular}

\section{b. Internal Consistency Reliability}

Pada Tabel 8 dan Tabel 9 merupakan skor composite reliability dan crobanch's alpha. Nilainya $(>0,7)$ dianggap variabel tersebut reliabel.

Tabel 8. Crobanch's Alpha Mahasiswa

\begin{tabular}{lccl}
\hline Variabel & $\begin{array}{c}\text { Cronbach's } \\
\text { Alpha }\end{array}$ & $\begin{array}{c}\text { Composite } \\
\text { Reliability }\end{array}$ & Keterangan \\
\hline ACC & 0,840 & 0,893 & \\
PEU & 0,900 & 0,922 & Reliabel \\
PU & 0,907 & 0,928 & \\
\hline
\end{tabular}

Tabel 9. Crobanch's Alpha Dosen

\begin{tabular}{llll}
\hline Variabel & $\begin{array}{l}\text { Cronbach's } \\
\text { Alpha }\end{array}$ & $\begin{array}{l}\text { Composite } \\
\text { Reliability }\end{array}$ & Keterangan \\
\hline ACC & 0,888 & 0,923 & \\
PEU & 0,910 & 0,932 & Reliabel \\
PU & 0,930 & 0,945 & \\
\hline
\end{tabular}

c. Average Variance Extracted (AVE)

Pada Tabel 10 dan Tabel 11 ditampilkan nilai AVE pada responden mahasiswa dan dosen yang $(>0,5)$ sama dengan valid dan telah memenuhi syarat.

Tabel 10. Skor AVE Mahasiswa

\begin{tabular}{|c|c|}
\hline Variabel & Nilai AVE \\
\hline $\mathrm{ACC}$ & 0,675 \\
\hline PEU & 0,664 \\
\hline $\mathrm{PU}$ & 0,683 \\
\hline \multicolumn{2}{|c|}{ Tabel 11. Skor AVE Dosen } \\
\hline Variabel & Nilai AVE \\
\hline $\mathrm{ACC}$ & 0,749 \\
\hline PEU & 0,697 \\
\hline $\mathrm{PU}$ & 0,743 \\
\hline
\end{tabular}

3.5 Evaluasi Model Struktural (Inner Model)

a. Path Coefficients $(\beta)$

Pada Tabel 12 dan Tabel 13, Path Coefficients $(>0,1)$ maka path berpengaruh pada model.

Tabel 12. Path Coefficients ( $\beta$ ) Mahasiswa

\begin{tabular}{cc}
\hline & Path Coefficients $(\beta)$ \\
\hline PEU $\rightarrow$ ACC & 0,200 \\
PU $\rightarrow$ ACC & 0,703 \\
\hline Tabel 13. Path Coefficients $(\beta)$ Dosen \\
\hline \multicolumn{2}{c}{ Path Coefficients $(\beta)$} \\
\hline PEU $\rightarrow$ ACC & 0,625 \\
PU $\rightarrow$ ACC & 0,331 \\
\hline
\end{tabular}

b. Coefficient of Determination $\left(\mathrm{R}^{2}\right)$

Nilai $\mathrm{R}^{2}$ mahasiswa variabel Acceptance of IT adalah 0,680 maka variabel PEU dan PU menjelaskan secara akurat (68\%) varian dari ACC dan sisa (32\%) dipengaruhi oleh faktor lain.

Nilai $\mathrm{R}^{2}$ dosen variabel ACC adalah 0,771 maka variabel PEU dan PU menjelaskan secara akurat $(77,2 \%)$ varian dari ACC dan sisa $(22,8 \%)$ dipengaruhi oleh faktor lain.

\section{c. Effect size $\left(\mathrm{f}^{2}\right)$}

Pada Tabel $14 \mathrm{f}^{2}$ mahasiswa PEU $\rightarrow$ ACC memiliki pengaruh kecil dan $\mathrm{PU} \rightarrow$ ACC memiliki pengaruh besar. Pada Tabel $15 \mathrm{f}^{2}$ dosen PEU $\rightarrow$ ACC memiliki pengaruh besar dan PU $\rightarrow$ ACC memiliki pengaruh kecil. 
Tabel 14. Skor $\mathrm{f}^{2}$ Mahasiswa

\begin{tabular}{|c|c|}
\hline & $\mathrm{ACC}$ \\
\hline$\overline{\mathrm{PEU}}$ & 0,091 \\
\hline PU & 1,123 \\
\hline \multicolumn{2}{|c|}{ Tabel 15. Skor $\mathrm{f}^{2}$ Dosen } \\
\hline & $\mathrm{ACC}$ \\
\hline PEU & 0,969 \\
\hline PU & 0,272 \\
\hline
\end{tabular}

\section{d. Predictive Relevance $\left(\mathrm{Q}^{2}\right)$}

Pada responden mahasiswa nilai $\mathrm{Q}^{2}$ Acceptance of IT adalah 0,440 maka nilai Q2 lebih besar dari nilai 0 dan seluruh variabel memiliki hubungan secara prediktif (predictive relevance). Pada responden Dosen diatas ditampilkan nilai $\mathrm{Q}^{2}$ Acceptance of IT berada diatas nilai 0 dan seluruh variabel memiliki hubungan secara prediktif (predictive relevance)

e. T-test

Uji T-statistic disajikan pada Tabel 16 dan Tabel 17.

Tabel 16. T-test Mahasiswa

\begin{tabular}{lccc}
\hline & $\begin{array}{c}\text { Original } \\
\text { Sample }\end{array}$ & T-statistic & P-values \\
\hline $\mathrm{PEU} \rightarrow$ ACC & 0,200 & 2,716 & 0,007 \\
$\mathrm{PU} \rightarrow$ ACC & 0,703 & 12,511 & 0,000 \\
\hline
\end{tabular}

Tabel 17. T-test Dosen

\begin{tabular}{lccc}
\hline & $\begin{array}{c}\text { Original } \\
\text { Sample }\end{array}$ & T-statistic & P-values \\
\hline $\mathrm{PEU} \rightarrow$ ACC & 0,625 & 6,511 & 0,000 \\
$\mathrm{PU} \rightarrow$ ACC & 0,331 & 3,622 & 0,000 \\
\hline
\end{tabular}

\subsection{Uji Hipotesis}

\section{a. Uji Hipotesis Mahasiswa}

H1: T-test 2,716 dengan besar signifikansi 5\% dan $\mathrm{P}$ values 0,007 , Maka $T$-test variabel PEU $\rightarrow$ ACC diatas dari 1,96 terdapat pengaruh siginifikan dan hipotesis 1 dinyatakan diterima.

H2: T-test 12,511 dengan besar signifikansi $5 \%$ dan Pvalues 0,000 , Maka $T$-test variabel $\mathrm{PU} \rightarrow \mathrm{ACC}$ diatas dari 1,96 terdapat pengaruh siginifikan dan hipotesis 1 dinyatakan diterima

H3: T-test PEU 2,716 dan T-test PU 12,511, maka PEU dan PU sama-sama berpengaruh signifikan terhadap ACC.

\section{a. Uji Hipotesis Dosen}

H1: T-test 6,511 dengan besar signifikansi 5\% dan Pvalues 0,003 , Maka $T$-test variabel PEU $\rightarrow$ ACC diatas dari 1,96 terdapat pengaruh siginifikan dan hipotesis 1 dinyatakan diterima.

H2: T-test 3,662 dengan besar signifikansi 5\% dan Pvalues 0,000 , Maka $T$-test variabel $\mathrm{PU} \rightarrow \mathrm{ACC}$ diatas dari 1,96 terdapat pengaruh siginifikan dan hipotesis 1 dinyatakan diterima
H3: T-test PEU 6,511 dan T-test PU 3,662, maka PEU dan PU sama-sama berpengaruh signifikan terhadap ACC.

\section{Kesimpulan}

Terdapat tiga hipotesis pada responden mahasiswa, yaitu variabel $\mathrm{PU} \rightarrow \mathrm{ACC}$ berpengaruh positif, $\mathrm{PEU} \rightarrow \mathrm{ACC}$ berpengaruh positif dan variabel PU dan $\mathrm{PEU} \rightarrow$ ACC sama-sama berpengaruh positif. Terdapat tiga hipotesis pada responden dosen, yaitu $\mathrm{PU} \rightarrow \mathrm{ACC}$ berpengaruh positif, $\mathrm{PEU} \rightarrow \mathrm{ACC}$ berpengaruh positif dan PU dan PEU $\rightarrow$ ACC sama-sama berpengaruh positif. Hipotesis pada responden mahasiswa dan dosen diterima dan berpengaruh positif terhadap penerimaan sistem e-learning. Pada responden mahasiswa variabel $\mathrm{PU}$ memiliki pengaruh dominan terhadap penerimaan sistem e-learning dengan nilai $T$ statistic 12,269 dan pada responden dosen PEU memiliki pengaruh dominan terhadap penerimaan sistem e-learning dengan nilai $T$-statistic 6,559 . Skor $R$-square ACC atau variabel endogen pada mahasiswa adalah 0,680 dan nilai ACC pada responden dosen adalah 0,772 berdasarkan nilai tersebut variabel eksogen PEU dan PU menjelaskan secara akurat.

\section{Daftar Rujukan}

[1]. Sukendro, S., Habibi, A., Khaeruddin, K., Indrayana, B., Syahruddin, S., Makadada, F. A., \& Hakim, H. (2020). Using an extended Technology Acceptance Model to understand students' use of e-learning during Covid-19: Indonesian sport science education context. Heliyon, 6(11), e05410. https://doi.org/10.1016/j.heliyon.2020.e05410

[2]. Almanthari, A., Maulina, S., \& Bruce, S. (2020). Secondary school mathematics teachers' views on e-learning implementation barriers during the COVID-19 pandemic: The case of Indonesia. Eurasia Journal of Mathematics, Science and Technology Education, 16(7), em1860. https://doi.org/10.29333/ejmste/8240

[3]. Hussein, Z. (2017). Leading to intention: The role of attitude in relation to Technology Acceptance Model in e-learning. Procedia Computer Science, 105, 159-164. https://doi.org/10.1016/j.procs.2017.01.196

[4]. Al Kurdi, B., Alshurideh, M., Salloum, S., Obeidat, Z., \& Aldweeri, R. (2020). An empirical investigation into examination of factors influencing university students' behavior towards elearning acceptance using SEM approach https://doi.org/10.3991/ijim.v14i02.11115

[5]. Maita, I., Indrajit, R. E., \& Irmayani, A. (2018, April). User behavior analysis in academic information system using unified theory of acceptance and use of technology (UTAUT). In Proceedings of the 2018 International Conference on Internet and e-Business (pp. 223-228). https://doi.org/10.1145/3230348.3230351

[6]. Al Kurdi, B., Alshurideh, M., \& Salloum, S. A. (2020). Investigating a theoretical framework for e-learning technology acceptance. International Journal of Electrical and Computer Engineering (IJECE), 10(6), 6484-6496. DOI: 10.11591/ijece.v10i6.pp6484-6496

[7]. Abdullah, F., \& Ward, R. (2016). Developing a General Extended Technology Acceptance Model for E-learning (GETAMEL) by analysing commonly used external factors. 
Computers in human behavior, 56, 238-256. https://doi.org/10.1016/j.chb.2015.11.036

[8]. Salloum, S. A., Alhamad, A. Q. M., Al-Emran, M., Monem, A. A., \& Shaalan, K. (2019). Exploring students' acceptance of $e$ learning through the development of a comprehensive technology acceptance model. IEEE Access, 7, 128445128462. Doi:10.1109/Access.2019.2939467

[9]. Al-Qaysi, N., Mohamad-Nordin, N., \& Al-Emran, M. (2020). A systematic review of social media acceptance from the perspective of educational and information systems theories and models. Journal of Educational Computing Research, 57(8), 2085-2109. https://doi.org/10.1177\%2F0735633118817879

[10]. Baber, H. (2021). Modelling the acceptance of e-learning during the pandemic of COVID-19-A study of South Korea. The International Journal of Management Education, 19(2), 100503. https://doi.org/10.1016/j.ijme.2021.100503 